\title{
Historically Underrepresented Students Redefining College Success in Higher Education
}

\author{
Delma Ramos ${ }^{*} \&$ Brenda Sifuentez ${ }^{2}$ \\ ${ }^{1}$ University of North Carolina at Greensboro \\ ${ }^{2}$ Lewis \& Clark College
}

\begin{abstract}
Extant definitions of college success largely focus on academic measures which include a limited set of indicators such as high-grade point averages, extra-curricular involvement, and leadership to denote a successful student. However, these definitions fail to measure the multiplicity of ways that students experience success in college, especially historically underrepresented college students (e.g., first-generation, low-income, students of color). Moreover, traditional conceptualizations of college success frame historically underrepresented students as deficient and as less likely to be successful, even though these students consistently have to overcome greater adversity during their college trajectories and consequently experience many victories that are not legitimized as a success. Therefore, the purpose of this article is to propose a more inclusive definition of the term college success that accounts for the diverse realities of historically underrepresented students and reveals the direct connection between student success and institutional success. The authors begin by historicizing the term college success, and how scholars, institutions, and students have come to define this concept, draw evidence from two research studies to illustrate their proposed definition of college success, and provide implications for research, practice, and policy.
\end{abstract}

* Contact:dmramos@uncg.edu 
Keywords: student success definition; institutional success; students of color; first-generation students; critical perspectives

College success is a term commonly used among U.S. higher education scholars, student affairs educators, and policymakers. However, there is disagreement on a definition of the term college success (Guess, 2008). Although the literature on topics related to college success is extensive (e.g., Engle \& Tinto, 2008; Higher Learning Commission, 2018; Willingham, 1985; Xiong et al., 2016), there are only a few scholarly pieces that offer an explicit definition for college success. Scholars propose that college success manifests in academic components including high-grade point averages, extra-curricular involvement, and leadership (Bean, 1980; Demetriou \& Schmitz-Sciborski, 2011; Venit, 2016; Willingham, 1985) that define who succeeds. Scholars also propose that college success consists of a collection of elements that ultimately lead to a student earning a college degree. Elements traditionally associated with college success include academic achievement (grades), retention, and persistence. However, these academic outcome measures are limited in their ability to expand our understanding of the ways students succeed in college as they fail to acknowledge the many challenges students face and to honor the multitude of strategies they engage to overcome these challenges. That is, focusing only on academic outcomes promotes a dominant narrative of what success in college looks like because this approach ignores the many successes students experience as they arrive at these traditional measures of college success. Furthermore, current definitions of the term also determine who is or can be successful in college. Specifically, the dominant narrative of college success frames historically underrepresented college students (e.g., first-generation, low-income, students of color) as deficient and as less likely to succeed, even though these students consistently have to overcome greater adversity during their college trajectories (Allen, 1992; Baker, 2013) and consequently experience many victories that are not legitimized as a success (securing food and housing, expanding educational opportunity, access to health care, etc.) under extant understandings of college success. Though these needs have been recently highlighted in a call for institutions to offer support to students in these areas (Higher Learning Commission, 2018), these victories remain unaligned with prominent academic outcome measures and expectations for success and continue to be generally perceived as taken for granted amenities.

\section{Purpose}

In contrast to this line of thinking, the purpose of this article is to disrupt traditional notions of the term college success by redefining the term to be more inclusive of the diverse realities of students historically underrepresented by providing examples from empirical research that demonstrate these ideas. Furthermore, we argue that students, as individuals, are not the only ones who benefit from achieving success in college and that institutions also experience gains as a result of students' mobilizing for success. For example, institutions strengthen their image through college success and become known for their support and effectiveness in recruiting and retaining historically under- 
represented students, which attracts more students to enroll. This article is outlined as follows: We begin by historicizing the term college success, and how institutions and students have come to define this concept. We then propose a more inclusive definition of college success in relation to students and institutions and present evidence from two research studies that help illustrate our proposed definition, challenge and add to the current discourse on college success, and shed light on the diverse ways students who are historically underrepresented experience success in college and how their success is directly linked to institutional success. Specifically, the latter point represents a call for institutions to grow their support of historically underrepresented student populations as their success directly benefits the institution.

\section{Historicizing the Term College Success}

Notions of college success first emerged between 1930 and 1960 when the federal government became initially concerned about student attrition or "student mortality" as it was referred to back then (Berger \& Lyon, 2005; Demetriou \& Schmitz-Sciborski, 2011; Venit, 2016). These ideas imply that historically, college success was equated with the terms college completion or college attainment. By the mid-1970s, the conversation on college success quickly evolved to one that focused on efforts that would counter the issue of student attrition. Influential models proposed student integration as a possible solution, suggesting that students who integrate into the college community are more likely to persist and graduate (Tinto, 1975). This work initially informed student engagement and programming efforts and continues to drive national dialogue on college success (Bean, 1980; Demetriou \& Schmitz-Sciborski, 2011; Venit, 2016).

As notions of college success continued to advance, so did institutional practices to collect data on the student experience. During the 1980s, higher education institutions began to collect more data on the students they enroll, including demographics and graduation rates (Hossler, 1984; Venit, 2016). This practice of collecting more data shifted the general conversation on student attrition to one concerned with the differing completion rates among college students from certain demographics, including historically underrepresented students (Venit, 2016). These concerns gave birth to college efforts that catered to specific groups of students, including those historically underserved. Consequently, this focus contributed to the creation of a narrative that standardized the definition of college success and created a deficit-based model for those who did not fit the current framing for college success. Moreover, conversations around college success during these five decades (1930-1980) highlight two college success indicators that continue to prevail today: student retention and student completion (e.g., Glenn, 2003; Oseguera et al, 2009). Retention refers to students completing their degrees at the institutions where they began their college journey, while completion indicates that students earned a degree (Hagedorn, 2005).

During the 1990s and 2000s, college success focused on the first-year experience or the experience of students during their first year in college, theorizing that students who 
successfully transitioned from high school to college were more likely to graduate (Swail, 1995). To these ends, programming efforts and collaboration across different campus services were at the forefront (Demetriou \& Schmitz-Sciborski, 2011; Thayer, 2000). These strategies defined a successful first-year transition as another college success indicator, especially for populations who showed lower completion rates. To date, these conversations remain present and continue to emphasize academic factors leading to student completion including retention and first-year transition (Venit, 2016). However, these conceptualizations limit our ability to expand our understanding of college success beyond general theories for completion.

\section{Institutional Definitions of a Successful College Student}

Research suggests that college success constitutes more than just attaining a degree (Turner, 2008). Therefore, institutions of higher learning are encouraged to expand their definition of a successful college student to include co-curricular indicators, such as on-campus involvement and leadership (Turner, 2008). Ideally, college success would capture the breadth and depth of the student experience. This idea aligns with studies conducted in the late 1970s that assessed how a group of nine higher education institutions perceived a successful student (Willingham, 1985). These elements embodied by successful students encapsulated the four years students spent in college pursuing an undergraduate degree. The rationale for capturing success over the four-year experience included the following principles: (1) elements of success do not manifest at the same time for all students in college, and (2) success looks different for students at different levels (first-year, sophomore, etc.). Characteristics of successful college students are comprised of: students' accumulated record of achievement over the four years including yearly grade point averages (GPA), and 10 marks under the following three measures: college and departmental honors, leadership (elected offices and appointments), and significant accomplishments. These marks include scientific, artistic, communication, physical, organizing, internships, and other independent achievements (Demetriou \& Schmitz-Sciborski, 2011; Willingham, 1985). Taken together, the elements manifested in a successful college student range from purely academic outcomes to achievement that incorporated involvement outcomes and other co-curricular accomplishments. These institutional considerations for student success remain focused on success explicitly situated within academic bounds and exclude the lived realities of students beyond the ivory tower. Especially, these metrics do not account for the nuances in the experiences of historically underrepresented college students.

\section{Students Defining Success in College}

In contrast with institutional definitions of a successful college student, student views support the premise that success in college is a highly individualized experience, and that success is often a subjective concept (Willingham, 1985). College success from the student perspective includes educational development or the acquisition of specialized skills including learning a new language, becoming aware of how the world works and 
societal dynamics that would serve students well upon graduation, critical thinking and analytical abilities, personal development such as the ability to work with others, receiving public recognition through academic achievement such as making the Dean's list or earning straight As, and goal attainment including degree completion (Cuseo, 2012; Willingham, 1985; Yazedjian et al., 2008). Once more, the college success considerations outlined from student perspectives do not center on the unique experiences of historically underrepresented students. Therefore, these ideas serve to reinforce the dominant discourse around the term. Albeit the unique needs of historically marginalized students are highlighted in a recent policy brief (Higher Learning Commission, 2018), this message urges institutions to better prepare to serve the unique needs of today's diverse college students but does not explicitly encourage institutions to alter their deficit views on college success of students from historically marginalized backgrounds as authors do in this article.

\section{New Directions: Redefining College Success}

It is important to underscore that the early conceptualizations of college success emerged from establishing a normative definition of the college experience as that of students pursuing degrees at four-year institutions to some extent, students attending highly selective institutions on the East Coast (Phillippe \& Patton, 2000), and from the notion that students attain a baccalaureate degree within four years. This proposition is exclusionary, outdated, and does not account for the diversity in college paths that began to develop as early as 1901, when the first community college was founded (Phillippe \& Patton, 2000). More importantly, research shows that a large proportion of historically underrepresented students begin their college career at community colleges (Crisp \& Nunez, 2014), which further supports our argument that normative definitions of college success invisibilize and cast a deficit light on the experiences of students historically underrepresented.

Additionally, while there is overlap in perceptions of what accounts for college success from historical institutional and student views, it is evident that college success goes beyond grades and grade point averages, though these measures are indicators of college completion (Gershenfeld et al., 2016). Yet, these elements of college success continue to exclude victories to lead to academic measures of college success. Given these considerations, we propose to redefine the term college success as follows: College success encompasses how students navigate the college context and overcome social, political, and economic disparity that work in tandem to limit opportunity and success in higher education, especially for historically underrepresented students. College success then becomes students' collection of obstacles defeated and benefits gained throughout the college experience. These benefits also serve to reshape the institutions they attend. To illustrate how their proposed definition of college success is operationalized, authors present qualitative findings from an unpublished transformative mixed methods study (Ramos, 2018), and findings from an unpublished critical ethnography (Sifuentez, 2019). The section that follows overviews both of the studies from which evidence is presented including 
study design and theoretical framings that connect with our proposed definition of college success.

\section{Methodology}

The larger transformative mixed methods study (Ramos, 2018) from which data were drawn to provide evidence to support our definition of college success took place in fall 2017. Participants of the study were undergraduate students in their senior year of college who identified as first-generation to college, low-income, and as students of color. Participants of the study were enrolled at one of seven four-year institutions of higher learning located in the Mountain region of the United States. Institutional types were as follows: three regional comprehensive universities (two of which are also Minority-Serving Institutions), two urban institutions (one of which has an access mission), one flagship institution, and one private institution. The purpose of the study was to identify, quantify, and describe participants' Funds of Knowledge (FK) defined as familial, cultural, and community assets (Moll et al., 1992; Velez-Ibanez, 1988; Velez-Ibanez \& Greenberg, 1992) and the strategies participants employed to leverage their assets in college. Therefore, the FK conceptual framework served as the theoretical foundation for this study (Moll et al., 1992; Velez-Ibanez, 1988; Velez-Ibanez \& Greenberg, 1992). The FK consist of essential skills and bodies of knowledge generationally developed, preserved, and transferred within households and their members. Specifically, FK are critical to ensure household survival and functioning (Moll et al., 1992; Velez-Ibanez, 1988; Velez-Ibanez \& Greenberg, 1992). The FK are diverse, ranging from occupation/household origin-specific knowledge to knowledge of the material and scientific. The FK are also embodied in strategies to cope with uncertainty caused by social, economic, and political disparities (Ramos \& Kiyama, 2021; Velez-Ibanez, 1988; Velez-Ibanez \& Greenberg, 1992) and are relevant beyond the household context. This theoretical framing is directly connected to our proposed definition of college success with its emphasis on students' victories achieved navigating inequality in their quest for college success. The data presented in the following section are findings from the qualitative phase of the study, which were collected via focus groups and individual semi-structured interviews with 13 participants. Although a sample of 745 students participated in the quantitative phase of the study, only 25 participants agreed to provide additional information during the qualitative phase. Due to scheduling issues, 13 participants were a part of the qualitative phase and represented only three of the seven research sites. Nonetheless, the sample size for the qualitative phase accounted for $10 \%$ of all students in the study who identified as first-generation, low-income, and a student of color, who represent the student population centered in the study. Qualitative data were analyzed using a list of a priori codes informed by FK, which served as the theoretical framing of the study.

The critical ethnography study (Sifuentez, 2019) involved an ethnographic inquiry on space and place at a Hispanic-Serving Institution (HSI) located in the Western region of the United States. As campuses are socially constructed by students, faculty, and 
staff, these spaces are also politicized, culturally relative, and historically specific (Rodman, 1992). Therefore, this inquiry draws upon the work of social theorists that incorporates the physical body and body discipline in the analysis of how power is employed through built environments (Low, 2009). The conceptual framework of the social construction of space accounts for the symbolic experiences of space that are intermediated by social processes, such as exchanges, conflict, and control (Low, 2009). The study spanned three years of participant observations, interviews, and archival documents. The purpose of this study was to identify space and place on a college campus to understand how campus landscape designs operate in relationship to the HSI designation, and how students influenced campus design plans for their own success. The data shared in this article are from interviews with 50 Latinx students where participants shared about spaces and places on campus that allowed them to thrive. The conceptual framework of the social construction of space is connected with our proposed definition of college student success as students embodied campus spaces to address campus climate issues and ultimately enhance their success. Below we present evidence from these two studies to help illustrate our proposed definition for college success.

\section{Findings from Ramos (2018)}

We present findings for this section through four narratives of victories participants experienced as part of achieving success in college that encourage scholar-practitioners to interrogate their understanding of college success. Participant name, place of residence, and institutional name provided are pseudonyms.

\section{Expanding Opportunity to Access Quality Education}

Tom identifies as a first-generation, low-income, man of color enrolled at Regional University. When Tom moved to Mountain City, he quickly learned he had limited educational options for high school, this awareness inspired him to seek out higher-quality education. Tom shares:

Because even though in high school, I lived close to the airport in Mountain City and I went to South East High School, which is about two hours away. So I had to, with me playing sports, I wouldn't get home before $10 \mathrm{pm}$. There were three buses to take me to school and then I transferred to the light rail and then walked the rest of the way. So, me doing that and still be able to finish [high] school and do good in sports was really good getting me to college.

In this quote, Tom demonstrates how he navigated the process of expanding access to college by enrolling in a high school that offered him more opportunities to become better prepared to college including quality education and co-curricular offerings. Although Tom had to spend much time away from home, he successfully expanded access to college by using public services. Furthermore, while college access and college success are commonly considered separate issues in higher education, both topics are 
naturally connected as students cannot succeed in college without first gaining access. In this case Tom illustrates how the strategic approach he took to pre-college preparation guaranteed his access to college.

\section{Alleviating Financial Stress}

Delia identifies as a low-income, first-generation, woman of color, who is also a mother of two children and the primary caretaker for her husband who is ill. Delia shared that after her husband developed a debilitating condition and could not work anymore, she found herself working too much while supporting her husband and children. Because of this, Delia had to stop out of college for a period of time. Managing multiple responsibilities led her to lose employment, which in turn prompted her to seek social welfare support. In her search for support, Delia explained how she was able to return to college:

Actually, the reason I could go back to school, my husband got, came down with a debilitating issue, and we had applied for disability and we were going through that process. And he couldn't work because of the disability but we had to have income. And I was trying to work too much. I ended up losing my job because I was taking him to too many doctor's appointments and doing things. So I lost insurance, I lost that, and we had to go in and get assistance. I had never had assistance prior to that. But when I went in, after I lost my job, all of a sudden, we had everything covered on his Medicaid, we had help with food. I could actually get assistance with after-school childcare. And I could either take classes or I had to find much work. Well, if I worked, we lost a lot of those benefits. So I was like, I'll go back to school. Yes, I took out a lot of student loans because I still had to pay bills that were over the extent of what a dorm, a traditional, college student would be because it was me supporting four people through student grants. I was actually able to do like PTA and parent things with them that I wasn't able to do when I was working two jobs trying to sustain everything. So actually in the long run it was much better once I figured out how to use the financial aid system, through DHHS [Department of Health and Human Services].

Through Delia's experience accessing welfare support, we learned that the welfare system quietly works to maintain those already disadvantaged that way. That is, if Delia would have chosen to remain employed, trying to manage multiple jobs, she would not have had the opportunity to return to college, spend time with her children, or support her husband's needs because the financial aid system would not have supported her fully. On the other hand, by opting to return to college and letting go of employment, Delia was able to make ends meet. She made the system work for her. Delia mobilized resources to mediate uncertainty and adversity caused by economic inequality and differential access to health care and education. 


\section{Relieving Stress through Religious Practice}

Angel identifies as a low-income, first-generation, man of color. Angel shared how religious involvement helps him overcome stress in college.

I'm really close to my community, especially my spirituality side, my religion. And, it obviously comes from my parents. When my dad got here to Mountain City, I think it was in the 1960's, Our Lady of Guadalupe was the only church that spoke and gave mass in Spanish. So, that's where I'm still serving as part of the youth group coordinator, and I'm still actively participating within my church community as well. I guess, the biggest benefit that I actually acquired through being spiritually influenced by my church community has been helping me reduce stress levels. Just having that moment with Jesus after being really stressed out, preparing for the week has helped me mentally and physically not be as overwhelmed or feel stressed out over a certain topic, or a certain issue that I've been facing. So, I want to say just my spirituality has definitely been a big part of helping me overcome certain complications throughout my career.

In Angel's experience spirituality through religion is a tool that has empowered him to manage stress. His account speaks toward reciprocity in the way Angel provides support to his community through leading the youth group and in exchange, he receives support in difficult situations. His story also offers a historical perspective about how his father identified a community to belong to through religion, in a place where Spanish was not widely spoken. Religion and spirituality play a critical role in Angel's ability to succeed in college, specifically, having a moment to share his concerns with Jesus and unwind as a new week approaches.

\section{Establishing a Support Network}

Vicky a student who identifies as a first-generation, low-income, woman of color spoke about how she established a support network of institutional agents (Stanton-Salazar, 2011) and community members to secure guidance and resources while in college.

What I would do is like, I'm not like a social person, I forced myself out of my shell freshman year. I would try to make a friend in every department and that way I knew I had at least one go-to person. And I was blessed even out of campus, like a church or just friendships and creating those things.

Unlike students who enroll in college with well-established networks to access resources and guidance, many historically underrepresented students like Vicky, must invest great energy and effort to build and expand their community to navigate and succeed in college. Vicky's narrative displays her efforts to create a community of support that included both college personnel and community stakeholders. Additionally, she demonstrates self-awareness and decides to push herself outside her comfort zone to grow a community of agents that would help provide holistic support. Furthermore, 
her strategy reveals Vicky's understanding of the diversity of needs and supports of college students and the importance of developing connections with various stakeholders to secure access to academic, social, and spiritual support.

Taken together, the four narratives we presented here from Ramos' (2018) study offer a deeper understanding about the ways in which historically underrepresented students achieve success in college. Though their journeys all culminated with the completion of a bachelor's degree, their true successes lie within overcoming inequity and adversity on their way to college and during college. Their narratives challenge traditional notions of college success as primarily composed of academic factors and help inform a new definition of college success that accounts for socioeconomic disparities that limit opportunity and success in higher education and honors the creative ways in which students operationalize their assets to navigate the normative college context.

\section{Findings from Sifuentez (2019)}

As previously stated, college success has been defined by normative metrics that focus on academic outcomes and less on victories of students as they move through completion of their college degree. In the section above, we presented evidence that showcased the victories minoritized students experienced as they worked to be successful in college. Their success translated into success metrics for the institutions they attended including retention rates, graduation rates, and post-graduation job placement. Consequently, these institutional performance metrics lead institutions to benefit from minoritized student success by increasing their profile as successful and effective institutions. This connection is important to highlight because it demonstrates how notions of college success extend beyond students' individual accomplishments and reshape the institutions they attend. Notions of college success are deeply rooted in neoliberalism. In other words, neoliberalism encompasses the deregulation of markets and mass privatization as it seeks to market and commodify goods for capitalistic gain. The characteristics of neoliberalism are consumerism, competitive individualism, surveillance, precarity, and declining morality (Museus \& LePeau, 2019). Precisely, we argue that beyond the neoliberal benefits of obtaining a college degree such as higher earning wages, health care, and upward social mobility, students have demanded change at institutions they attend by pushing for an inclusive campus environment that is supportive. Below we present evidence from the critical ethnography on space and place (Sifuentez, 2019) to support this part of our definition.

\section{Students Physically Transforming Campus Environments}

The physical buildings of college campuses are often viewed as spaces that provide students the ability to engage in learning and with offices on campus in order to have successful and beneficial experiences throughout their time at an institution. When discussing a certain locale, the terms space and place are often used to reference each other; however, DeCerteau (1984) described space as an embodied experience. Space is 
the movement and articulation of different social practices. On a college campus the buildings, greenery, and other objects are located in relation to each other in space; however, it is the interactions and movements within this space that situate the campus as a place.

It is the interactions and movements on college campuses that allow institutions to also reshape themselves physically. As buildings and open spaces come to form an embodied experience for students, faculty, and staff, it became apparent that for minoritized students, campus spaces were not welcoming of their identity. The awareness of minoritized students feeling unwelcome and afraid was due to the escalated number of hostile campus climate incidents. The increasingly hostile environment as well as being the only institution within their state system to not have a cultural center, created a movement to include a campus cultural center in the extension plans. Students organized rallies and demonstrations and created petitions to have the cultural center created on campus. After several roadblocks, students eventually were able to identify an existing campus space that could be a cultural center.

The campus design plans demonstrated that a quad area on campus was designed as a walkway in order to connect buildings while providing shade from the sun so that students could study outside. However, as student activism increased due to the lack of a cultural space on campus, students would identify the quad as a place where social justice events could occur. Despite the architectural goal for the quad design to function as a connector space, student organizers envisioned this quad to be a cultural space that would be:

A location where students of color and their intersectional identities can share space collectively and create coalition, education, and social justice. A space for students of color to find support until each identity space requested from students is staffed, funded, supported as a working center.

The center for many students is space where their identities are acknowledged and their ability to speak to the institution regarding their needs becomes viable and normalized. This space was demanded and created by the students as a means to ensure their success at the institution. It was more than a social justice quad, but rather a symbolic representation of their needs and how they could influence the institution. While the original architectural intent of the quad space was to create links between buildings, the social justice quad which now houses the cultural center activates the pathway as an event space. The social justice quad is a space where events, teach-ins, and performances occur that align with social justice as defined by students on campus.

The push to create a social justice quad was not rooted in the individual benefit of college success but rather in the collective of the student body. If all students felt as though they had a space that embodied their identities, their success and legacy would be valued beyond a graduation rate. Lucia stated, "My success here is more than just graduating. It is about leaving this campus better. After I graduate I want my younger siblings to come here and not experience the same hostile campus environment." This 
is an example of how student success can have a nuanced interpretation of how institutions can also be impacted and benefit from structural changes.

\section{Students Reshaping the Student Body}

Several Latinx students spoke about the importance of leaving the institution in "a better place than we found it." One way students put this in motion was to create a high school conference targeted at recruiting Latinx students to college. The conference was conceptualized as a way to do student-to-student recruitment. Funding came directly from the student organizational budget with assistance from the student government. For the first annual conference, over 100 Latinx students attended from local high schools. Diana shared feelings of how empowered she felt:

We had high school students asking us, so how do I get here? I want to do what you are doing. I think a lot of us felt empowered to know that we can give somebody else the information about college, that we didn't have and that the institution doesn't give.

This example demonstrates how students can conceptualize their success as sharing knowledge with others, in this case other Latinx students.

With little institutional support a Latinx student group was able to expose college as a possibility to local area high school Latinx students. Mara stated "we really don't have the resources to get connected with universities, or how to do the [admissions] process. For me being able to spread that knowledge and show them it's here and its possible, I really like that." Not only did students see themselves as people that could share knowledge regarding the college admission process, but they also discussed the importance of having students see themselves on a college campus. Enrique stated:

Obviously, you don't see us [Latinx students] as a norm on college campuses but here we are. Even though I know we [Latinx students] have to fight for resources, we want them [high school students] to know that this campus is for us, this space is for us, we are meant to be here.

The organizers of this conference stated that the goal was to "expand access but to also show people that we are here." While the purpose of this conference was directed to Latinx high school students, it was also a way that students shared their college success with other Latinx students. The conference demonstrated that college campuses can be a space for Latinx students. As a result of the first conference, five students enrolled at the institution in the following academic year. One of the five students ended up participating as a planning committee member for the subsequent year.

The social justice quad created a space where students felt ownership of the campus and the conference expanded opportunities for students to continue to define and articulate what success looks for the collective. They were able to dictate how their success is a community effort and in turn advanced the institutions' capacity to provide support for minoritized students on campus. Furthermore, this idea also posits that students' success generates more student success for incoming minoritized students. The exam- 
-ples provided from Sifuentez (2019) portray the institutional transformation component of our proposed definition of college success. Specifically, students' mobilization to transform their current institution into a campus environment supportive of their needs leaves a legacy that supports both future generations of students and enhances the institution.

\section{Discussion and Recommendations}

The purpose of this article was to propose a definition of college success that disrupts and adds to dominant and normative understandings of the term, especially pertaining to students from historically marginalized communities. Therefore, we defined college success as: College success encompasses how students navigate the college context and overcome social, political, and economic disparity that work in tandem to limit opportunity and success in higher education, especially for historically underrepresented students. College success then becomes students' collection of obstacles defeated and benefits gained throughout the college experience. These benefits also serve to reshape the institutions they attend. This definition of college success intends to be both more inclusive of the unique experiences of students who are historically underrepresented in college and highlights the connection between student success and institutional transformation as a direct benefit institutions gain from student success. To illustrate this proposed definition, authors provided evidence from two research studies.

Ramos' (2018) transformative mixed methods study provided evidence of the diverse ways college success manifests in the experience of students from historically marginalized communities (expanding opportunity to access quality higher education, alleviating stress, navigating financial hardships, expanding their support network). Student success from this perspective lies within overcoming inequity and adversity as students navigate the college context. Most importantly, their narratives disrupt normative framings of college success as they highlight a multitude of milestones and victories often erased from traditional academic measures of college success present in extant literature. For instance, participants from (Ramos, 2018) express our proposed definition of college success by narrating how they charted a strong path to and through college. They did so by expanding opportunity to access quality education, identifying resources to address financial struggles, establishing networks of support, and leaning on spiritual and religious practices to relieve stress. In this manner, the findings presented also unveil socioeconomic disparities sustained by societal systems that shape college access and success in higher education for historically underrepresented students.

Similarly, Sifuentez's (2019) study provided evidence that supports our assertion that college success encompasses more than the individual student experience and accounts for both collective student success and tangible institutional benefits via institutional transformation (students transforming the physical campus, students reshaping the student body). Students identified that their success was intertwined with the ability to 
see themselves on campus and have a collective space that they could call their own. Through their activism and ability to transform a space into a place allowed for their success to be connected to the success of the institution. The creation of the social justice quad not only serves as a space for events and teach-ins, but it is also now a part of retention efforts that was created by students for students. Although this space is student-led, the institution has benefitted from this space. The campus transformation that occurred was not only a physical change, but it also created the ability for the administration to capitalize on the space as a recruitment and retention tool. In addition, the conference serves as a way that students are able to influence the make of the student body by demonstrating to local Latinx high school students that attending this institution is possible. The findings demonstrate how students' collective work in creating a space that was grounded in social justice and intersectionality transformed the institution that allowed them to be successful. Yet this same success also translated to the success of the institution as it aided in the retention and recruitment of students.

Taken together, the findings presented demonstrate that college success is much more than an individual effort; it is the combination of overcoming multiple systemic barriers placed in front of marginalized students to prevent them from accessing and attaining higher education. The findings from both of these studies demonstrated that students do not succeed individually but rather with help of a collective. Students demonstrated that overcoming social, political, and economic disparities that could have limited their opportunities were mitigated through support of others, therefore shifting the direction of how practitioners and researchers should conceptualize college success beyond the individual's ability to graduate. Furthermore, our findings allow us to honor and legitimate the small victories students achieve in their quest to attain a college degree and center their agency and power within to improve their experience in college while reshaping the institutions they attend.

\section{Recommendations for Research}

The ideas presented in this article warrant recommendations for research. First, our proposed definition of college success is a call for scholars to reassess the ways they conceptualize and incorporate these notions in research. Specifically, we encourage scholars to move away from normative notions of college success that do not accurately examine the unique ways that students who are historically underrepresented experience success in college.

Secondly, our findings highlight specific factors of student success not traditionally measured in research; thus, we urge scholars to consider these ideas in the design of research to more comprehensively study how students experience college success. Especially, our findings highlight areas of need that are often invisible when studying academic measures as indicators of college success but represent significant challenges for students from underrepresented backgrounds to succeed in college. Third, we urge scholars to retain a focus on structural inequality and its role in shaping student success in college. For instance, societal forces (economic disparity, discrimination, inequitable 
access to health care) that negatively impact student trajectories to and through college. This idea also requires an examination of structures that support students to navigate inequality including community resources and networks of support outside the institution.

Fourth, our research presents implications for future research on college success to expand our understanding of the connection between student success and institutional success. Precisely, as we discussed in this article, institutions experience benefits as a result of students thriving in their campuses. Conceptualizing college success as multidirectional and fluid allows the student and the institution to enter into a partnership that is not solely concentrated on individualism but a collective. Specifically, this notion takes the pressure off the student to be the sole person responsible for navigating the challenges of college knowing their institution is responsible to have structures for success in place. By making this shift students are working in tandem with the institution to create equitable environments.

\section{Recommendations for Practice}

The implications for research we presented above are directly connected to implications for practice. First, given the normative ways of defining success that emphasize academic achievement and campus engagement, practitioners must recognize that student success is a process that is inevitably shaped by the background of students and the context within which they exist. This idea aligns with a holistic view of students that considers their unique lived realities and their connection to college success. We urge practitioners to examine any assumptions and biases they may possess about how students succeed in college, especially students from underrepresented backgrounds. Refraining from imposing dominant narratives of student success on all students empowers practitioners to expand their understanding of college success as well as the diverse challenges students may encounter during their college careers. At the same time, this approach empowers both practitioners and students to celebrate the victories that occur as students progress toward degree completion. This shift in thinking also allows practitioners to recognize the complex connection between student success and institutional success and effectiveness.

Second, based on our findings, we urge practitioners to become aware of and knowledgeable of the various resources within their communities that can support student success. These resources may include food pantries, mental health resources, transportation services, local shelters, and other social support for which students may qualify. We propose documenting these resources and making them available to other practitioners and faculty to share with students they support.

Third, we recommend practitioners to take a step back and examine the institutional and external contexts within which students live and identify structures, policies, and practices that can prevent students from succeeding in college. Some examples of these include: immigration laws; institutional, state, and federal financial aid policies; orient- 
-ation programs' cost and requirements, which may be prohibitive for some students and their families; academic probation policies and their connection with academic performance and financial aid; institutional communication about important deadlines and degree progression requirements; etc. Practitioners may assume that all students are aware and know how these structures, policies, and practices function; however, it is important to recognize that this is not true for all students and intentionality about this issue is key in supporting student success.

Fourth, one of the main arguments we pose in this article is that student success benefits both students and the institutions they attend. Thus, by promoting awareness of this connection, we expect practitioners to identify ways in which more resources can be invested to support student success beyond the traditional programs and offices. Specifically, resources to support student activism and advocacy as these efforts promote success for students and enhance the image of the institution. By doing this, practitioners can support current and future students in a holistic manner.

\section{Recommendations for Policy}

College success is often tied to state and federal funding, and it is difficult for individual institutions to move beyond traditional matrices of time to completion, graduation, and job placement in order to receive support and funding. However, we advocate that institutions should use government and community relations offices to lobby federal and state legislative policy makers beyond sharing institutional quantitative data on college success. The sharing of qualitative data brings to light that success is beyond the individual and is a key component in changing institutional culture centered on equity. Student affairs practitioners and governmental and community relations offices could work together to find student success stories. An institutional lobby day on the state and federal level would bring students together to share their success stories while also exposing them to the legislative process and gaining more advocacy skills.

Secondly, as students navigate through institutional structures there is also a need for the institution to examine relationships with local entities. The establishment of local community relations with the institution can enhance the support of student and institutional success. Developing relationships with local governments could lead to the establishment of local ordinances that support students through affordable housing and food security, which can lead to more student success.

Finally, while we recognize that institutions are often bound by outside structures, we recommend examining how institutional policies can enhance student success. As we stated earlier, one way to do this is by reviewing campus policies regarding activism, allocation of institutional space for minoritized students, and academic probation. In addition to a review of these policies, we urge institutional policy makers to recognize that student success is institutional success beyond graduation rates, that policy changes and call to actions by students and their activism will led to creating a campus that approaches success holistically, and that students' efforts to be successful can change the 
culture of an institution to become more equitable.

\section{Conclusion}

In order to better support the success of students, institutions of higher education must reconsider the ways they define and measure student success. Interrogating current understandings of student success can empower their institutions to better respond to the unique needs of students on campus. Furthermore, student success should be viewed as a multidirectional endeavor impacting both students and institutions. However, it is important to note that student success does not always translate to economic gain for the institutions and students but can also encompass institutional transformation. The students' experiences described in this manuscript sought to influence the operational patterns of the institutions and to provide an expanded understanding of what college success looks like to further inform the work of scholars, practitioners, and policy makers.

\section{References}

Allen, W. (1992). The color of success: African-American college student outcomes at predominantly White and historically Black public colleges and universities. Harvard Educational Review, 62(1), 26-45. https://psycnet.apa.org/ doi/10.17763/haer.62.1.wv5627665007v701

Baker, C. N. (2013). Social support and success in higher education: The influence of on-campus support on African American and Latino college students. The Urban Review, 45(5), 632-650. https://doi.org/10.1007/s11256-013-0234-9

Bean, J. P. (1980). Dropouts and turnover: The synthesis and test of a causal model of student attrition. Research in Higher Education, 12(2), 155-187. https://doi. org/10.1007/BF00976194

Berger, J. B., \& Lyon, S. C. (2005). Past to present: A historical look at retention. In A. Seidman (Ed.), College student retention: Formula for student success (pp. 1-30). Praeger.

Crisp, G., \& Nuñez, A. M. (2014). Understanding the racial transfer gap: Modeling underrepresented minority and nonminority students' pathways from two-to four-year institutions. The Review of Higher Education, 37(3), 291-320. https:// doi.org/10.1353/rhe.2014.0017

Cuseo, J. (2012). Student success: A shared responsibility. Presented at the Kentucky Association for Developmental Education, Western Kentucky University, Bowling Green, KY.

De Certeau, M. (1984). The practices of everyday life. University of California Press. 
Demetriou, C., \& Schmitz-Sciborski, A. (2011). Integration, motivation, strengths and optimism: Retention theories past, present and future. In R. Hayes (Ed.), Proceedings of the 7th national symposium on student retention, 2011, Charleston (pp. 300-312). Norman, OK: The University of Oklahoma.

Engle, J., \& Tinto, V. (2008). Moving beyond access: College success for low-income, first-generation students. Pell Institute for the Study of Opportunity in Higher Education.http://www.pellinstitute.org/publications-Moving_Beyond_Access_2008.shtml

Gershenfeld, S., Ward Hood, D., \& Zhan, M. (2016). The role of first-semester GPA in predicting graduation rates of underrepresented students. Journal of College Student Retention: Research, Theory \& Practice, 17(4), 469-488. https://doi. org/10.1177\%2F1521025115579251

Glenn, F. S. (2003). The retention of Black male students in Texas public community colleges. Journal of College Student Retention: Research, Theory \& Practice, 5(2), 115-133. https://doi.org/10.2190\%2FGYEU-WWER-N8W7-XTBK

Guess, A. (2008, May 20). Defining college success. Inside Higher Education. https:// www.insidehighered.com/news/2008/05/20/board

Hagedorn, L. S. (2005). How to define retention: A new look at an old problem. In A. Seidman (Ed.), College student retention (pp. 89-105). Praeger Publishers.

Higher Learning Commission. (2018). Defining student success data initiative: Recommendations for changing the conversation. https:/download.hlcommission.org/ initiatives/StudentSuccessConversation.pdf

Hossler, D. (1984). Enrollment management: An integrated approach. The College Board.

Low, S. (2009). Towards an anthropological theory of space and place. Semiotica, 175, 21-37. https://doi.org/10.1515/semi.2009.041

Moll, L. C., Amanti, C., Neff, D., \& Gonzalez, N. (1992). Funds of knowledge for teaching: Using a qualitative approach to connect homes and classrooms. Theory into practice, 31(2), 132-141. https://doi.org/10.1080/00405849209543534

Museus, S. D., \& LePeau, L. A. (2019). Navigating neoliberal organizational cultures: Implications for higher education leaders advancing social justice agendas. In Kezar, A. \& Posselt, J. (Eds.), Higher Education Administration for social justice and equity in higher education: Critical perspectives for leadership and decision making, (pp. 200-224). Routledge.

Oseguera, L., Locks, A. M., \& Vega, I. I. (2009). Increasing Latina/o students' baccalaureate attainment: A focus on retention. Journal of Hispanic Higher Education, 8, 23-53. https://doi.org/10.1177/1538192708326997

Phillippe, K. A., \& Patton, M. (2000). National profile of community colleges: Trends and statistics. American Association of Community Colleges. 
Ramos, D. M. (2018). Funds of knowledge and the college success of first-generation students, low-income students, and students of color: A transformative mixed methods study. [Unpublished Doctoral dissertation, University of Denver]. ProQuest Dissertations \& Theses Global.

Ramos, D. \& Kiyama, JM. (2021). Tying it all together: The core tenets of funds of knowledge. Educational Studies. Advance online publication. https://doi.org/10.1 080/00131946.2021.1904932

Rodman, M. C. (1992). Empowering place: Multilocality and multivocality. American Anthropologist, 94(3), 640-656.

Sifuentez, B. L. J. (2019). Assembling a Hispanic-Serving Institution: A Campus Landscape Analysis of a Hispanic-Serving Institution. [Unpublished Doctoral Dissertation, University of Denver]. ProQuest Dissertations \& Theses Global.

Stanton-Salazar, R. D. (2011). A social capital framework for the study of institutional agents and their role in the empowerment of low-status students and youth. Youth \& Society, 43(3), 1066-1109. https://doi. org/10.1177\%2F0044118X10382877

Swail, W. S. (1995). The development of a conceptual framework to increase student retention in science, engineering, and mathematics programs at minority institutions of higher education [Unpublished doctoral dissertation]. George Washington University.

Thayer, P. B. (2000). Retention of students from first generation and low-income backgrounds. Opportunity Outlook, 11, 2-8.

Tinto, V. (1975). Dropout from higher education: A theoretical synthesis of recent research literature. Review of Educational Research, 45(1), 89-125. https://doi. org/10.3102\%2F00346543045001089

Turner, S. (2008). Measuring college success: Evidence and policy challenges. In M.S. McPherson \& M. O. Schapiro (Eds.), College success: What it means and how to make it happen (pp. 119-129). The College Board.

Vélez-lbáńez, C. G. V. (1988). Networks of exchange among Mexicans in the US and Mexico: Local level mediating responses to national and international transformations. Urban Anthropology and Studies of Cultural Systems and World Economic Development, 17(1), 27-51.

Vélez-Ibañez, C. G. V., \& Greenberg J. (1992). Formation and transformation of Funds of Knowledge among U.S.-Mexican households. Anthropology and Education Quarterly, 23(4), 313-335.

Venit, E. (2016, December 6). The evolution of student success. Student Success Insights Blog. https://www.eab.com/blogs/student-success-insights/2016/12/ evolution-of-student-success

Willingham, W. W. (1985). Success in college: The role of personal qualities and academic ability. The College Board. 
Xiong, S., Allen, C., \& Wood, J. L. (2016). The role of community college counselors as validating agents on men of color student success. Community College Journal of Research and Practice, 40(6), 558-561. https://doi.org/10.1080/10668926.2015 .1096222

Yazedjian, A., Toews, M. L., Sevin, T., \& Purswell, K. E. (2008). "It's a whole new world": A qualitative exploration of college students' definitions of and strategies for college success. Journal of College Student Development, 49(2), 141-154. https://doi.org/10.1353/csd.2008.0009 